\title{
EFFECT OF DIFFERENT METHODS OF TRAINING IN BODY COMPOSITION AND LIPID PROFILE IN OCCUPATIONAL MEN
}

\author{
Marjiana Ângela Zin ${ }^{1}$, Gisele Maria Tonin da Costa ${ }^{2}$, Rodrigo Poderoso de Souza ${ }^{3 *}$, \\ Andrigo Zaar $^{4}$ \\ 1 Institute of Educational Development of Alto Uruguai, Getúlio Vargas, Rio Grande do Sul, Brazil. ${ }^{2}$ \\ Institute of Educational Development of Alto Uruguai, Getúlio Vargas, Rio Grande do Sul, Brazil. ${ }^{2}$ \\ Center Univercity Fundation Assis Gurgacz, Cascavel, Paraná, Brazil. ${ }^{4}$ Faculty of Technology Nova \\ Palhoça. Florianópolis, Santa Catarina, Brazil. \\ * Autor correspondente: https://orcid.org/0000-0002-7590-3015
}

DOI: $10.35984 /$ fjh.v2i1.107

\begin{abstract}
Obesity is increasingly present in the population and raises the risk of death from cardiovascular diseases. The objective of this study was to investigate changes in body composition, total cholesterol, LDL, HDL and triglycerides of obese adults. The sample was costituida twelve male volunteers subjected to hold a bone densitometry analysis with body composition (DEXA) and examinations that incaram plasma concentrations of total cholesterol, LDL, HDL and triglycerides in the blood. The volunteers were inserted into three training models: aerobic training (AeT), anaerobic training (AnT) and concurrent training (CT). The training period was twelve weeks, with three sessions per week lasting 60 minutes. The AeT group took part in running sessions with cycling sessions. The AnT group performed bodybuilding exercises. The CT group combined the two previous models, with no gap between them. All variables were tested for normality of distribution by the Shapiro-Wilk test. For those who presented normality, the paired teste test was used for comparison before and after training (mean \pm standard error). All analyzes were performed by the Statistical Package for the Social Sciences (SPSS) version 21.0. A significance level of $\alpha=0.05$ was used. When comparing the initial and final periods of intervention was observed reductions in variables: total weight, body fat weight and visceral fat weight in all groups. Total cholesterol decreased only in the CT group. Already, the LDL cholesterol decreased in the AnT and CT groups, being that in the CT with greater notoriety. HDL cholesterol increased in all groups, and in the AnT with greater notoriety. The plasma triglyceride concentration decreased only in the AeT and CT groups. The data suggest that the concurrent training is effective for the reduction of obesity when compared to the aerobic and anaerobic methods.
\end{abstract}

Keywords: Methods of training, body composition, lipid profile.

\section{INTRODUCTION}

Obesity characterized by excess fat present in an individual may be accompanied by glucose intolerance, insulin resistance, dyslipidemias, hypertension, increased visceral adipose tissue and increased risk of coronary heart disease and cancer (MCARDLE et al., 2003).

Obesity and overweight kill around 2.8 million people per day, mainly in developed countries (ACSM, 2009). In Brazil, about $40 \%$ of the population has an inadequate body fat index for the age group, and when adiposity is distributed in the waist region, they increase the chances of metabolic disorders associated with cardiovascular disease (ZAAR et al., 2014).

Currently the fight against obesity is carried out through dietary, drug and surgical manipulation, since the causes that have greater association with overweight 
and obesity are according to the metabolism. In this way multidisciplinary teams composed by doctors, psychologists and nutritionists were created, however these strategies seem not to be enough to reduce the obesity indices. Therefore, the objective of the present study was to verify the effect of different training methods on body composition and lipid profile of obese men.

\section{METHODOLOGY}

The research is pre-experimental in nature. This research model consists of the application of experiments with non-randomly formed sample groups, which are performed with the purpose of controlling the action of possible intervening factors and investigating degrees of change resulting from specific interventions in the dependent variables. All participants read and signed the informed consent form (TCLE).

The sample was selected for non-random convenience. The following inclusion criteria were established: a) not to perform regular physical activity in addition to the training prescribed during the study; b) have no limitations or injuries that could interfere with training; and c) do not control food or ingest substances that could influence the interpretation of results. The study was conducted in accordance with the Helsinki Declaration and the International Committee of Medical Journal Editors (BAILAR and MOSTELLER, 1988).

Twelve male volunteers $(41.51 \pm 10.98$ years, $72.03 \pm 12.94 \mathrm{~kg}, 171.94 \pm 10.33$ $\mathrm{cm}$ ), active and overweight or obese were included in the analysis performed by the index of body mass (BMI) (Table 1). The sample was randomly divided into four groups: anaerobic training $(\mathrm{N}=04)$, aerobic training $(\mathrm{N}=04)$ and concurrent training $(\mathrm{N}=04)$. These volunteers underwent a lipid profile analysis through laboratory tests, which identified the levels of total cholesterol (TC), HDL, LDL and triglycerides (TG). Besides the lean body mass, fat mass, muscle mass and visceral (Table 3).

Table 1. Characteristics of the participants presented in mean \pm sd.

\begin{tabular}{lcccc}
\hline Group & Body mass $\mathbf{( k g )}$ & $\begin{array}{c}\text { Age } \\
\text { (years) }\end{array}$ & Height $\mathbf{( c m )}$ & BMI \\
\hline AnT & 83,21 & 32,50 & 1,70 & 28,8 \\
CT & 108,43 & 29,55 & 1,80 & 33,4 \\
AeT & 84,76 & 29,50 & 1,66 & 30,8 \\
Mean $\pm d p$ & $92,1 \pm 14,11$ & $30 \pm 1,76$ & $1,72 \pm 0,1$ & $31,0 \pm 2,3$ \\
\hline
\end{tabular}

AnT: Anaerobic Training; CT: Concurrent Training; AeT: Aerobic Training; BMI: Body Mass Index

The lipid profile and body composition evaluations were performed pre-training program and after 90 days of training. In the evaluation, participants were submitted to the following blood tests: total cholesterol; HDL; triglyceride; Cholesterol test; LDL. The X-ray absorptiometry technique was used to evaluate the body composition using the Lunar iDXA device from GE Healthcare. Participants were familiarized with the procedures for two sessions prior to initiating the intervention. AeT Group: Comprised of a running session or a session of cilcism, three times a week with a load corresponding to 7 on the BORG Scale, with a 2:1 ratio (2 minutes of running and 1 minute of recovery), recovery corresponded to a load 3 in the BORG Scale. AnT Group: Compound by squatting on the bar; horizontal supine; armrest; leg press; pulled high; seated paddling; I sink with free weight; cross over; pullover; triceps forehead; 
threading biceps and development, all of them divided into 3 weekly sessions. The volunteer performed 3 sets of 8 to 12 maximal repetitions per exercise, with a load corresponding to 7 of the BORG Scale and a recovery of 1 minute. CT Group: Composed by the combination of the two physical training models previously mentioned. In this training model different energy sources are requested, being one predominantly aerobic (running) and one with neuromuscular anaerobic predominance (resistance exercise). In the three training sessions, resisted exercises and walking / running were performed, both in the same training session, with no interval from one to the other. All variables were tested for normality of distribution by the Shapiro-Wilk test. For those who presented normality, the paired teste test was used for comparison before and after training (mean \pm standard error). All analyzes were performed by the Statistical Package for the Social Sciences (SPSS) version 21.0. A significance level of $\alpha=0.05$ was used.

\section{RESULTS}

This study verified the effect of different training methods on overweight or obese men. There was a reduction in the variables total weight, body fat weight and visceral fat weight in all groups. There was a reduction in total cholesterol only in the CT group. There was a decrease in LDL cholesterol in the AnT and CT groups. Increased HDL cholesterol in all groups. The plasma triglyceride concentration decreased only in the AeT and CT groups. In relation to adipose tissue, it is observed that the trained groups had lower percentage values for this variable. The AnT and CT groups reduced adipose tissue, however, the AeT showed a lower percentage among the trained groups.

Table 2. Anthropometric parameters of individuals before and after training.

\begin{tabular}{|c|c|c|c|c|c|c|c|c|c|}
\hline \multirow{2}{*}{$\begin{array}{l}\text { Parameters } \\
\text { Anthropometric }\end{array}$} & \multicolumn{3}{|c|}{ AnT } & \multicolumn{3}{|c|}{$\mathrm{AeT}$} & \multicolumn{3}{|c|}{ CT } \\
\hline & Pre & Post & $P$ & Pre & Post & $P$ & Pre & Post & $P$ \\
\hline $\begin{array}{l}\text { Body Weight } \\
\qquad(\mathrm{kg})\end{array}$ & $\begin{array}{l}83.23 \\
\pm 4.64\end{array}$ & $\begin{array}{l}82.96 \pm \\
4.30\end{array}$ & 0.013 & $\begin{array}{r}84.75 \\
\pm 4.32\end{array}$ & $\begin{array}{l}83.89 \pm \\
4.26\end{array}$ & $<0.001$ & $\begin{array}{l}108.45 \\
\pm 4.46\end{array}$ & $\begin{array}{l}105.78 \\
\pm 4.21\end{array}$ & $<0.001$ \\
\hline BF (\%) & $\begin{array}{l}31.41 \\
\pm 0.98\end{array}$ & $\begin{array}{l}30.72 \pm \\
1.39\end{array}$ & 0.062 & $\begin{array}{r}31.98 \\
\pm 1.57\end{array}$ & $\begin{array}{l}30.74 \pm \\
1.91\end{array}$ & $<0.001$ & $\begin{array}{r}38.57 \\
\pm 1.86\end{array}$ & $\begin{array}{l}36.02 \pm \\
1.37\end{array}$ & 0.134 \\
\hline LLM (kg) & $\begin{array}{l}55.21 \\
\pm 3.68\end{array}$ & $\begin{array}{c}55.5 \pm \\
4.27\end{array}$ & 0.541 & $\begin{array}{l}55.59 \\
\pm 2.90\end{array}$ & $\begin{array}{l}56.34 \pm \\
3.25\end{array}$ & 0.021 & $\begin{array}{r}64.59 \\
\pm 2.56\end{array}$ & $\begin{array}{l}64.96 \pm \\
2.73\end{array}$ & 0.078 \\
\hline $\mathrm{FM}(\mathrm{Kg})$ & $\begin{array}{l}25.22 \\
\pm 2.55\end{array}$ & $\begin{array}{c}24.65 \pm \\
2.68\end{array}$ & 0.077 & $\begin{array}{l}26.53 \\
\pm 2.94\end{array}$ & $\begin{array}{c}24.76 \pm \\
2.87\end{array}$ & 0.177 & $\begin{array}{r}40.38 \\
\pm 2.58\end{array}$ & $\begin{array}{l}38.77 \pm \\
2.41\end{array}$ & 0.216 \\
\hline MM (kg) & $\begin{array}{r}66.49 \\
\pm 3.15\end{array}$ & $\begin{array}{l}67.70 \pm \\
2.79\end{array}$ & 0.074 & $\begin{array}{r}65.63 \\
\pm 1.69\end{array}$ & $\begin{array}{l}66.88 \pm \\
1.25\end{array}$ & 0.026 & $\begin{array}{r}59.63 \\
\pm 3.55\end{array}$ & $\begin{array}{l}60.82 \pm \\
2.79\end{array}$ & 0.067 \\
\hline VF (kg) & $\begin{array}{l}1.11 \pm \\
2.01\end{array}$ & $\begin{array}{l}1.08 \pm \\
1.80\end{array}$ & 0.007 & $\begin{array}{r}0.805 \\
\pm 2.27\end{array}$ & $\begin{array}{c}0.647 \pm \\
1.99\end{array}$ & $<0.001$ & $\begin{array}{l}1.35 \pm \\
2.48\end{array}$ & $\begin{array}{l}1.11 \pm \\
2.12\end{array}$ & $<0.001$ \\
\hline
\end{tabular}

Presentation of variables with mean \pm standard deviation. AnT: Anaerobic Training; AeT: Aerobic Training; CT: Concurrent Training; BF: Body Fat; LLM: Lean Body Mass; FM: Fat Mass; MM: Muscle Mass; VF: Visceral Fat. $<0,05$ (significantly different). Paired-test was used to compare before and after training in the same group. 
Differences were observed between the groups in the analysis of Total Cholesterol (TC), High Density Lipoproteins (HDL), Low Density Lipoproteins (LDL) and Triglycerides (TG) when comparing pre and post training program data (Table 3).

Table 3. Pre and Post-program training results in the TC, HDL, LDL and TG of the study participants in mean \pm sd.

\begin{tabular}{|c|c|c|c|c|c|c|c|c|}
\hline Group & Pre & $\begin{array}{c}\text { TC } \\
\text { (mg/dl) } \\
\text { Post }\end{array}$ & $\begin{array}{l}\text { HDL } \\
\text { (mg/dl } \\
\text { ) Pre }\end{array}$ & $\begin{array}{l}\text { HDL } \\
\text { (mg/dl } \\
\text { ) Post }\end{array}$ & $\begin{array}{c}\text { LDL } \\
\text { (mg/dl) } \\
\text { Pre }\end{array}$ & $\begin{array}{c}\text { LDL } \\
\text { (mg/dl) } \\
\text { Post }\end{array}$ & $\begin{array}{c}\text { TG }(\mathrm{mg} / \mathrm{dl}) \\
\text { Pre }\end{array}$ & $\begin{array}{c}\text { TG }(m g / d l) \\
\text { Post }\end{array}$ \\
\hline AnT & 197 & 208 & 50 & 56 & 118,8 & 118,6 & 141 & 167 \\
\hline $\mathrm{CT}$ & 169 & 145 & 43 & 42 & 110,8 & 88,4 & 76 & 73 \\
\hline $\mathrm{AeT}$ & 125 & 145 & 33 & 37 & 61 & 80 & 154 & 142 \\
\hline $\begin{array}{l}\text { Média } \pm \\
\text { dp }\end{array}$ & $\begin{array}{c}163,67 \pm 36 \\
31\end{array}$ & $\begin{array}{c}166 \pm 36 \\
37\end{array}$ & $\begin{array}{c}42 \pm 8 \\
54\end{array}$ & $\begin{array}{c}45 \pm 9 \\
85\end{array}$ & $\begin{array}{c}96,87 \pm 31 \\
32\end{array}$ & $\begin{array}{c}95,67 \pm 20 \\
30\end{array}$ & $\begin{array}{c}123,67 \pm 41 \\
79\end{array}$ & $\begin{array}{c}127,33 \pm 48 \\
69\end{array}$ \\
\hline
\end{tabular}

TC: Total Cholesterol; TG: Triglyceride; HDL: High Density Lipoproteins; LDL: Low Density Lipoproteins; $\mathrm{mg} / \mathrm{dl}:$ milligrams/deciliter

When we observed the lean body mass, the AnT group was superior to the mean values of the CT. Still in this case, CT was shown to be slightly higher than the AeT group.

\section{DISCUSSION}

This study investigated the effect of different training methods on body composition and lipid profile with overweight and obesity men. There is an increase in $\mathrm{HDL}$ and CT in the AnT group and reduction of LDL. Corroborating with the researches of Ferreira and Póvoa, (1999); The high levels of HDL exhibit a relation of lower risk of heart disease even compared to subjects with CT below the borderline, leaving it to be understood that the effect of the applied AnT may have positively influenced the participant's lipid profile. However, TG levels increased considerably, but it should be noted that no diet was applied during the twelve weeks of intervention in any of the groups and this may have a direct influence on this increase. In the CT group there was a reduction in CT, HDL, LDL and TG after intervention. In the AT group there was a reduction in $T G$ and an increase in $\mathrm{HDL}$, corroborating with the literature that indicates greater emphasis on aerobic exercise to reduce plasma triglyceride levels and increase HDL levels (SBC, 2007). Other differences were observed between the groups in the comparative analysis regarding $M C, M M$ and $M G$ before and after the training program. The $C T$ and $A e T$ groups reduced $M C$ and $M G$, but a larger reduction was observed in the CT group when compared to the TA group.

The problem of obesity and overweight is related to the evolution, or regression, of current lifestyles in modern societies. In fact there was a technological evolution, which made our daily tasks easier. But there was also a drastic reduction in the amount and quality of daily physical activity. The causes that lead or predispose to overweight and obesity are according to behavioral influences the quality and quantity of physical activity, quality and quantity of nutrition, being smoker and socioeconomic conditions. According to the metabolism namely the genetic, metabolic and endocrine factors, besides race, gender, age, and gestational state. 
Namely, the components of daily energy expenditure, the resting metabolic rate which is the energy needed to maintain our vital functions, and accounts for about 50 to $70 \%$ of daily energy expenditure. The digestion of food that corresponds to $10 \%$ of the daily energy expenditure. And the physical activity that is the component that we can change effectively and can change the other two in a favorable or unfavorable way.

Regarding the resting metabolic rate, the amount of muscle mass is an aspect that influences it by increasing it. Particularly if muscle mass predominantly has type II muscle fibers. In fact it is not muscle mass that has an energy expenditure / $\mathrm{kg}$ of mass higher. Organs like brain, heart, liver and kidneys possess more, yet the muscle mass of the human body is larger than these organs. Thus, in a woman weighing $55 \mathrm{~kg}$ and $21-25 \%$ fat and a man weighing $75 \mathrm{~kg}$ and $15-19 \%$ fat, it is possible to observe that the contribution to the value of the metabolic rate of daily rest by the organs is at most about $709 \mathrm{kcal} /$ day. In turn, fat contributes about $64.1 \mathrm{kcal} /$ day and muscle with about $226.2 \mathrm{kcal} /$ day in women and $331.5 \mathrm{kcal} /$ day in man.

Regarding the type of exercise and the energy cost, predominantly aerobic exercises seem to have a higher cost compared to strength exercises. In fact, predominantly aerobic exercises require a greater amount of muscle mass in general, while strength exercises are more localized. However the intensity of the exercise is that it plays a key role. Strength exercises involving large muscle masses and with a high intensity around $70 \%$ of $1 \mathrm{RM}$ can present high energy cost per minute values and are equivalent to aerobic training.

The problem is in the methodologies used to calculate the energy cost in the physical exercise. The most widely used and viable method is the quantification of $\mathrm{VO}_{2}$ and the production of $\mathrm{CO}_{2}$ (carbon dioxide), although this method is valid to quantify the energy cost in predominantly continuous aerobic exercises where there is a stabilization of $\mathrm{O}_{2}$ consumption, it does not have this capacity in high intensity and intermittent efforts, such as strength, where the predominant energy is lactic anaerobic. In this way, we can not establish a direct relationship between $\mathrm{O}_{2}$ consumption and energy cost. In fact, there is no valid method to measure the energy cost via the lactic anaerobic route, perhaps because of this lower energy cost values are presented in the strength exercises.

Fernandez et al (2004) conducted a study to evaluate the effect of anaerobic physical exercise on body fat mass with obese adolescents compared with aerobic exercise. The finding did not present significant differences between the groups, but a decrease in the body mass index, when compared to the initial and final values of the training in each individual. This finding corroborates the fact that even without a restrictive diet, physical exercise is capable of promoting a significant mass loss in biological terms.

The process of choosing the most appropriate training protocol is extremely important for the goal to be achieved. The proposed training programs activate different metabolisms of energy generation, the aerobic metabolism of moderate intensity, is the one used to reduce the corporal grading. In fact, the biochemical adaptations induced by continuous exercise have been studied since the late 1960's and it has been definitively proven that this type of activity induces an increase in the oxidative capacity of the muscle, by the increase in the activity of key enzymes of betaoxidation, a specific metabolic pathway for the oxidation of fatty acids, and also to signal and increase the speed of other metabolic pathways of the oxidative metabolism of ATP (adenosine triphosphate) resynthesis, such as the Krebs cycle and the mitochondrial respiratory chain (MOREIRA 2008).

FAG Journal of Health - ISSN 2674-550X, 2020, v.2, n.1, p. 16

DOI: 10.35984/fjh.v2i1.107 
However, the effects of high intensity anaerobic exercises, especially those using resisted exercise, are still poorly understood. Therefore, ACSM (2009) recommends the maintenance of lean mass as an integral part of a physical exercise program, which reduces the risk of developing diseases, such as disturbances in lipid metabolism, fat levels found in the blood circulation, and in the concentrations of its components such as total cholesterol, HDL cholesterol, LDL cholesterol and triglycerides are directly associated with the evolution of atherosclerosis.

Guttierres and Marins (2008) reinforce that the anaerobic training can contribute in an effective way in the reduction of the corporal weight and bring improvements in the lipid profile. The acute modifications are those of the own energy cost for the accomplishment of activity and in the recovery phase. Chronic effects are provided by changes in the resting metabolic rate. The factor most responsible for modifying the resting metabolic rate is lean mass gain. In order to measure total energy expenditure during strength training, the greatest difficulty is found in the standardization of studies in relation to the intensity and volume used, besides, the post-exercise moment is not taken into account, making it difficult to compare the data (GUTTIERRES ET MARINS, 2008). It can be verified through the high-intensity anaerobic method that post-exercise oxygen consumption (COPD) can remain high for up to twelve hours (FOUREAUX et al., 2006), so concurrent training seems to be the best strategy for weight loss, where the aerobic component will promote $\mathrm{VO}_{2}$ increase and the anaerobic component maintenance of lean mass. Therefore, a training program without dietary control may be effective in reducing obesity and lipid profile in obese men.

When checking the changes in body composition caused by different models of physical training, the use of different training methods contribute to the reduction of adipose tissue, since there is a need to increase the basal metabolic rate, these protocols may be part of a physical exercise program for this population.

New studies should be conducted considering a control group and the influence of diet on the analyzed parameters.

\section{CONCLUSION}

Based on the objectives and results presented, it is verified that the concurrent training is effective for the reduction of obesity when compared to the aerobic and anaerobic methods.

\section{REFERENCES}

ABESO. Available at: www.endocrino.org.br/nota-oficial-abeso-e-sbem>. Accessed on: 07 jun. 2017.

AMERICAN COLLEGE OF SPORTS MEDICINE. Appropriate Physical Activity Intervention Strategies for Weight Loss and Prevention of Weight Regain for Adults. Medicine \& Science in Sports \& Exercise. [S.I.], vol. 41, no. 2, pg. 459-471, Feb. 2009.

BAILAR, John C .; MOSTELLER, Frederick. Guidelines for statistical reporting in articles for medical journalsamplifications and explanations. Annals of Internal Medicine, v. 108, n. 2, p. 266-273, 1988. 
CAYRES, S.U. CHRISTOFARO, D.G.D. OLIVEIRA, B.A.P. ANTUNES, B.M. SILVEIRA, L.S FREITAS JÚNIOR, I.F. Concurrent training and functional training promote beneficial changes in body composition and non-alcoholic hepatic steatosis of obese youngsters. Physical Education Journal / UEM. Vol. 25, No. 2, p. 285-295, 2nd trimester. 2014.

FERNANDEZ, A.C. MELLO, M.T. TUFIK, S. CASTRO, P.M. FISBERG, M. Influence of aerobic and anaerobic training on body fat mass of obese adolescents. Revista Brasileira de Medicina do Esporte. São Paulo, vol. 10, no. 3, p. 152-158, May / June 2004.

FERREIRA, C., PÓVOA, R. Cardiology for the General Practitioner. São Paulo: Atheneu, 1999.

FOSS, M.L. KETEYIAN, S. J. Physiological bases of exercise and sport. RJ: Guanabara Publisher Koogan S.A. 2000.

FOUREAUX, G. PINTO, K. C. DÂMASO, A. Effect of excessive oxygen uptake after exercise and the resting metabolic rate in energy expenditure. Revista Brasileira de Medicina do Esporte. São Paulo, vol. 12, no. 6, pg. 393-398, Nov-Dec, 2006.

GUYTON, A. Human physiology and disease mechanism. Rio de Janeiro: Guanabara Koogan, 6. ed., 1998.

GODOY-MATOS, A.F. OLIVEIRA, J. Overweight and obesity: Diagnosis. Brazilian Society of Endocrinology and Metabology. Aug. 2004. Available at: <www.endocrino.org.br/obesidade/>. Accessed on: 07 jun. 2016.

GUTTIERRES, A.P.M. MARINS, J.C.B. The Effects of Strength Training on the Risk Factors of the Metabolic Syndrome. Brazilian Journal of Epidemiology. Juiz de ForaMG, vol, 11, no 1, pg. 147-158, 2008.

MCARDLE, W. D., KATCH, F. I., KATCH, V. L. Fundamentals of Exercise Physiology. Rio de Janeiro: Guanabara Koogan, 2. ed., 2003.

MOREIRA, M.M. SOUZA, H.P.C. SCHWINGEL, P. A. COUTO DE SÁ, C.K. ZOPPI, C.C. Effects of aerobic and anaerobic exercise on cardiac risk variables in overweight adults. Brazilian Archives of Cardiology. Salvador, vol. 91, no. 4, p. 219-226, 2008.

NAHAS. Markus V .; Physical Activity, Health and Quality of Life: concepts and suggestions for an active lifestyle; Midiograf; Londrina, 2001.

PRADO, E.S. DANTAS, E.H.M. Effect of aerobic physical exercise and strength on lipoproteins HDL, LDL and lipoprotein (a). Brazilian Archives of Cardiology. São Paulo, vol. 79 , no. 4 , p. 429-433, 2002.

BRAZILIAN CARDIOLOGY SOCIETY. III Brazilian Guideline on Dyslipidemias and Prevention of Atherosclerosis. Brazilian Archives of Cardiology. v. 77, n. 3, Aug, 2001. 
BRAZILIAN CARDIOLOGY SOCIETY. IV Brazilian Guideline on Dyslipidemias and Prevention of Atherosclerosis. Brazilian Archives of Cardiology. v. 88, n. 1, Apr, 2007.

SBEM. Available at: www.endocrino.org.br/cbem-2014-emagrecer-com-ou-sematividade-fisica > Accessed on: 07 jun. 2016

VASCONCELlLOS, S.A. NASCIMENTO, G.R. LEONE, M.L. PEREIRA, E. FERNANDO, M. A review on concurrent training. Essays and Science: Biological, Agrarian and Health Sciences. Campo Grande / BR, vol. 12, no.2, pg17-33, 2008.

ZAAR, A. REIS, V.M. SBARDELOTTO, M.L. Effects of a physical exercise program on blood pressure and anthropometric measures. Revista Brasileira de Medicina do Esporte. Vol. 20, no. 1, p. 13-16, Jan / Feb 2014. 